\title{
CONCEPÇÕES DE MUNDO SOBRE O CONCEITO DE FRIO: UMA ANÁLISE SOBRE O DISCURSO DOS ESTUDANTES
}

\author{
Apresentação: Comunicação Oral \\ Artur Torres de Araújo ${ }^{1}$; Eliemerson de Souza Sales ${ }^{2}$; Francivaldo Balbino da Silva ${ }^{3}$; \\ Jacqueline Morais da Costa ${ }^{4}$; Petronildo Bezerra da Silva ${ }^{5}$
}

\begin{abstract}
Resumo
Este artigo é um pequeno recorte de uma pesquisa de mestrado de Educação em Química e fundamenta-se nas ideias da educação problematizadora do Paulo Freire e dos perfis conceituais do Eduardo Mortimer. Segundo Freire, antes do estudante ter os primeiros contatos com os conceitos formais que são ensinados na escola, os mesmos já tiveram seus primeiros contatos com a maioria destes conceitos por meio de sua convivência diária, dos conhecimentos passados de pai para filho e entre os indivíduos de uma sociedade, que são os conhecimentos de senso comum. Geralmente os conhecimentos do senso comum são muito resistentes por parte dos indivíduos que o possuem, logo, acredita-se ser de bom alvitre não confrontá-los diretamente, mas criar situações em que os próprios indivíduos possam perceber que tal conhecimento é equivocado ou incompleto. Nessa perspectiva, este trabalho visou a identificação do conhecimento de mundo de alguns estudantes acerca do conceito de frio, para isso foram utilizados textos contendo concepções históricas, sociais, culturais, geográficas, ontológicas e filosóficas sobre o tema frio e por meio deste texto os estudantes tinham que responder 3 questões também com o mesmo caráter do texto. Após a aplicação do texto, e análise das respostas produzidas pelos estudantes, foram identificadas 4 visões distorcidas a respeito do conceito de frio, e uma a respeito do tempo. Para os estudantes, o frio é uma substância, uma reação do corpo, mudança de clima, para climas mais chuvosos ou nublados, causa doenças como a gripe, leptospirose entre outas. E Tempo é sinônimo de clima.
\end{abstract}

Palavras-Chave: Frio; Concepção de mundo; Ensino de Ciências Naturais.

\footnotetext{
1 Doutorando pelo Programa de Pós-Graduação em Ensino das Ciências - PPGEC/UFRPE e Professor de Educação em Química da Universidade Federal de Pernambuco - UFPE, arturdesume@hotmail.com

2 Mestrando do Programa de Pós-Graduação em Educação em Ciências e Matemática - PPGECM/UFPE e Professor de Educação em Química da Universidade Federal de Pernambuco - UFPE, eliemersonsales@gmail.com

${ }^{3}$ Licenciatura Plena em Química, Universidade Estadual da Paraíba - UEPB, fan.assuncao@gmail.com

${ }^{4}$ Doutoranda em Química, Universidade Federal da Paraíba - UFPB, Jacqueline_morais@hotmail.com

${ }^{5}$ Doutor em Educação, Professor da Universidade Federal de Pernambuco - UFPE, npk@bol.com.br
} 


\section{Introdução}

Historicamente, observa-se a suma importância da concepção de que a aprendizagem se dá através de um envolvimento ativo do aprendiz na construção do conhecimento. Nessa perspectiva construtivista, os estudantes vão construindo representações mentais do mundo ao seu redor, que são usadas para interpretar novas situações e guiar as tomadas de decisões.

Com isso, a aprendizagem é vista como processo adaptativo, no qual os esquemas conceituais do aprendiz são progressivamente reconstruídos de modo a atingirem um alcance cada vez maior em relação às ideias e experiências (MORTIMER, 1994).

$\mathrm{Na}$ perspectiva freireana, a educação deve ser concebida como um processo incessante, inquieto e, sobretudo, permanente de busca ao conhecimento, em oposição ao que o autor denominou de educação bancária, caracterizada pela transmissão acrítica e apolítica do conhecimento. A educação bancária assume o conhecimento "como uma doação dos que se julgam sábios" (Freire, 2005). Por outro lado, na pedagogia problematizadora, o professor deve suscitar nos estudantes o espírito crítico, a curiosidade, a não aceitação do conhecimento simplesmente transferido. Os educadores têm "como uma de suas tarefas primordiais [...] trabalhar com os educandos a rigorosidade metódica com que devem se aproximar dos objetos cognoscíveis" (Freire, 2006). A aprendizagem acontece com a formulação e a reformulação dos saberes pelos estudantes ao lado dos professores, igualmente sujeitos do processo.

Para Mortimer (1994), existem algumas condições para que uma nova maneira de entender os fenômenos seja aceita: a insatisfação do estudante com suas concepções anteriores, e a nova concepção se mostrar inteligível, plausível e frutífera na solução de novas questões.

Segundo Araújo (2015) o frio é um tema pouco pesquisado e que raramente aparece como foco de pesquisas no ensino de ciências, assim o autor destaca que são identificadas nos discursos dos estudantes algumas visões distorcidas a respeito do frio.

Diante disso, esse trabalho objetiva investigar quais os "conhecimentos de mundo" que os estudantes apresentam a cerca da temática frio. 


\section{Fundamentação Teórica}

\section{Conceitos e Conceituação}

A ideia de "conceito" mais aceita atualmente é a que o entende como modelo ou esquema mental construído pelo aprendiz para representar objetos ou eventos, e que se torna relativamente estável quando possuído por um indivíduo. Quando um modelo individual passa por algum tipo de transformação, acredita-se que ocorreu uma evolução conceitual. Esse processo pode significar a aprendizagem do estudante (MORTIMER, SCOTT e ELHANI, 2011).

A conceituação é um processo de construção de conceitos que tem origem na interação social situada entre um indivíduo e alguma experiência externa. O pensamento conceitual é limitado pelos significados de certos conceitos dominados pelos indivíduos. Os processos de socialização são fortes, pois indiciam a sensação de que "possuímos" conceitos em nossa mente.

$\mathrm{Na}$ concepção Vigotskiana, o pensamento conceitual é uma tendência ou potencialidade de permanência nessa sensação, quando plenamente desenvolvido. Como processo emergente, tende a repetir características aparentemente centrais, que nos permitem usar conceitos repetidamente, e com isso efetivamente pensamos através de conceitos e nos comunicamos por meio dos signos da linguagem (VYGOTSKY, 1978).

A distinção entre sentido e significado amplia o entendimento do que é permanente na conceituação:

o sentido de uma palavra é o agregado de todos os fatos psicológicos que surgem em nossa consciência em consequência da palavra. O sentido é uma formação dinâmica, fluida e complexa que tem várias zonas que variam em sua estabilidade. Em diferentes contextos, o sentido de uma palavra muda (VYGOTSKI, 2000).

A construção social conhecida como "significado" torna possível a subjetividade, e as pessoas tem a possibilidade de compartilhar o significado de uma palavra, ainda que sentidos atribuídos a ela sejam divergentes. Dessa forma, a palavra se torna portadora do conceito.

Essas construções sócio culturalmente estáveis são bases para contratos de comunicação (ROMMETVEIT, 1979). A aprendizagem de um conceito está diretamente ligada à aprendizagem do seu significado, transpassando sentidos pessoais para significados socialmente aceitos. A formação de sentido é um desenvolvimento meramente pessoal. Cada indivíduo gera diferentes sentidos para uma mesma palavra e pode também variar nos sentidos gerados a critério do contexto. 
Em uma sala de aula podemos perceber a diversidade de pensamentos e maneiras que os estudantes demonstram de ver e descrever o mundo ao seu redor. Será que tais ideias devem ser desprezadas? Ou será que podemos construir um conhecimento significativo com essa heterogeneidade de ideias e linguagens expressas nas aulas de química?

Mortimer (1994, 1995) considerou a diversidade de linguagem e pensamento nas salas de aulas de ciências e propôs os "perfis conceituais" como uma maneira de modelar essa heterogeneidade do pensamento verbal em salas de aulas de ciências. Os perfis conceituais devem representar modelos de diferentes maneiras de ver e representar o mundo, utilizadas pelas pessoas para dar significado a sua vivência.

Os perfis conceituais surgiram como complementaridade ao modelo de mudança conceitual de Posner e colaboradores (1982), divergindo fortemente de uma ideia central de que estudantes deveriam ser levados a romper com suas concepções prévias ao aprender ciências. Tal divergência aproxima os perfis conceituais com o construtivismo conceitual de William Cobern (1996), que também propõe a coexistência de diferentes modos de pensar e falar como resultado da aprendizagem de ciências.

A ideia de perfil conceitual pode ser usada para descrever a evolução e estruturação de ideias de determinado conceito, que acontece no ambiente social da sala de aula e também individualmente, que se deriva do processo de ensino. O perfil conceitual é inspirado na ideia de perfil epistemológico de Bachelard (1978) que defende a ideia de que conceitos estão em pleno desenvolvimento, ligados a algumas visões filosóficas derivadas do seu estágio de maturidade, uma única visão filosófica explica apenas uma fração do conceito.

O perfil conceitual apresenta linearidade com ideias de perfil epistemológico, como a divisão de características entre diferentes zonas do perfil, cada zona sucessiva contém poder explicativo mais abrangente do que as anteriores. Com isso, a aprendizagem é entendida como a migração para novas zonas num perfil conceitual, que não precisam abandonar ideias presentes em outras zonas, mas deve-se ter consciência da interação entre as diferentes zonas conceituais e em qual contexto cada zona pode ser usada.

A análise do perfil conceitual orienta na percepção de características de uma zona conceitual como obstáculos epistemológicos e ontológicos que dificultam a construção de zonas mais avançadas.

No espaço escolar, apesar de cada estudante ter perfis diferentes, suas características dentro de uma mesma cultura são as mesmas para cada conceito. O trabalho de Mortimer (1996) a história das ideias científicas, pode ser usado para identificar zonas científicas e précientíficas. 


\section{Metodologia}

Este trabalho possui uma abordagem qualitativa, e foi desenvolvido em uma escola pública na cidade de João Pessoa - Paraíba, tendo como sujeitos 40 estudantes do terceiro ano do Ensino Médio.

Os passos metodológicos se estruturaram da seguinte forma, a saber: primeiramente foi desenvolvido um texto contendo concepções históricas, filosóficas, políticas, culturais e geográficas a cerca da evolução do conceito de frio. No sentido de identificar as concepções prévias dos estudantes, foram desenvolvidas 3 questões em que os estudantes deveriam expor suas ideias a respeito da temática abordada. Essas questões apresentavam um caráter investigativo e versavam sobre entendimentos históricos, sendo relacionados com entendimentos cotidianos. E por fim, os estudantes se reuniram em grupos de 4 componentes para debaterem a respeito do texto e das ideias que deveriam expressar em suas respostas.

Ressaltamos que, por questões éticas, serão utilizados nomes fictícios para identificar os sujeitos desta pesquisa.

\section{Resultados e Discussão}

Para discussão e análise dos dados, serão expostas transcrições literais das respostas dos estudantes acerca das questões colocadas no texto. No entanto, ressaltamos que, para as discussões colocadas aqui, não serão considerados os erros ortográficos, de concordância, regência verbal e nominal expostos pelos estudantes, apenas as ideias que os mesmos tentaram expor respondendo as questões do texto.

\subsection{Primeira questão: experiência cotidiana sobre o frio}

$\mathrm{Na}$ primeira questão os estudantes são indagados a responder com base nas suas experiências cotidianas, o que é o frio e quais os seus efeitos?

Nenhuma das respostas expressou uma ideia científica a respeito do frio, as respostas sobre o que é o frio, foram exposições do que se acredita ser suas experiências cotidianas ou ideias que foram passadas pelos seus familiares mais velhos e integrantes da sua comunidade.

As ideias dos efeitos do frio expostas pelos estudantes estão intimamente ligadas as suas experiências vivenciadas, afirmam que os efeitos do frio são a gripe, arrepios na pele, doenças, chuvas, inundações, leptospirose, fadiga, sono, entre outras. 
Essas ideias expostas pelos estudantes são oriundas do senso comum, são aquelas ideias passadas de pai para filho, ideias compartilhadas em seu meio geográfico e social, e demostram também a linguagem coloquial. Podemos observar estas ideias na transcrição abaixo:

"Frio é uma sensação que sai do nosso corpo quanto temos contato com o vento, água, gelo ou algumas coisas do tipo. Seus efeitos são arrepios, o corpo fica gelado, os lábios roxos e o corpo tremulo e o frio em exeto pode levar a morte" (João)

As transcrições abaixo evidenciam respostas que provavelmente foram tiradas de uma pesquisa da internet, onde claramente o calor é tratado como uma substância (o frio seria a "falta de calor num corpo"), entretanto as ideias estão em discordância com os conceitos científicos em vigência (os corpos não possuem calor). No entanto, na linguagem coloquial, podemos nos deparar com esses conceitos distorcidos, na convivência diária, nos meios sociais, até mesmo por pessoas do meio acadêmico.

\footnotetext{
"Não se saber ao certo podia ser uma substância, um processo, ou algum estado de existência especial uma força real não identificada e sim questionada e o efeito causado é um ar extremamente frio que chega a causar efeitos congelantes" (José).
}

“O frio é a sensação produzida pela falta de calor num corpo ou matéria, causada pela baixa temperatura atmosférica ou por meios artificiais através de refrigeração. Os efeitos dos frios podem causar queimaduras ou a hipotermia que acentuada da temperatura corpórea, em um nível menos grava pode causar fadiga, moleza, tremores, câimbras e dores" (Marta).

Na primeira transcrição abaixo os estudantes entendem o frio como sendo uma massa que claramente expõe uma ideia do frio como sendo uma substância. Na segunda transcrição abaixo os estudantes entendem o frio como sendo a mudança do clima quando o clima fica chuvoso ou com neblina.

Apesar das respostas dos estudantes serem inadequadas do ponto de vista científico, a segunda transcrição abaixo relaciona o frio com climas de temperaturas baixas.

"O frio pra mim e uma massa fria que ocorre quando as partículas se contraem e casam frio e quando esfria muito lava a se pegar um resfriado” (Maria). 
"Frio e uma mudanço climático, que ocorre durante a chuva, tempo nublado ou a ausência do calor. Asma, cala frio, nariz intupido falta de calor são um dos efeitos" (Pedro).

\subsection{Segunda questão: o frio e a história}

Analisando as respostas dos estudantes, foram identificadas as seguintes ideias a respeito da segunda questão, onde os estudantes deveriam refletir e argumentar se o frio poderia mudar o curso da história.

A maioria das respostas foi satisfatória e concordante com as ideias do texto e com algumas ideias científicas atuais, expressando ideias como: o frio poderia mudar o curso da história e destacaram fenômenos naturais e sociais que seriam acarretados pelo frio elevado, afirmando que muitos seres vivos morreriam, a tecnologia se renovaria, as plantações congelariam, a comida ficaria escassa e mais cara, o que poderia ocasionar ataques e motins a armazéns e mercados.

Um grupo que equivale a $10 \%$ dos estudantes citou o filme "Um Dia Depois de Amanhã” que retrata o aquecimento global provocando alterações climáticas extremas causando devastações e uma era glacial no planeta. Estas ideias contidas nas respostas dos estudantes estão transcritas abaixo:

\footnotetext{
"Sim, o filme "um dia depois de amanhã" mostra o que aconteceria se o mundo viesse a ser tão frio sofrer, o caos seria grande os fazendeiros iriam sofrer porque não teria como plantar nem colher nada por conta do frio. As pessoas poderiam até deixar de sair tanto de casa porque toda vez que fosse sair teria que vestir muitas roupas quentes" (Pedro).
}

"Sim, por que mudaria draticamente a economia, clima, o modo de viver e esse fatores mudariam o curso da História” (Joana).

"Sim pois a cada estudo acontece novas descobertas, com isto outras invecões e assim faz com que tanto a tecnologia se renove quanto a história” (Marcos).

A resposta transcrita abaixo, apesar de concordar que o frio pode mudar o curso da história, traz uma ideia totalmente diferente das ideias contidas no texto, chegando a afirmar absurdamente que se não fosse às épocas de frio o vulcão não evaporaria.

"Sim, pois as épocas de frio naquela época teve uma influência no aumento vulcânico, pois se não tivesse essas épocas de frio o vulcão não ia evaporar" (Sergio). 
A resposta transcrita abaixo é um trecho do texto, por isso essa resposta não expressa às ideias desses estudantes a respeito do enunciado.

"Embora não haja consenco alguns climatoloco acreditam ter sido a agitação solo"

\subsection{Terceira questão: frio e economia}

Analisando as respostas dos estudantes, foram identificadas as seguintes ideias a respeito da terceira questão onde os estudantes deveriam discutir como o frio elevado pode afetar a economia de uma nação.

A maioria das respostas dos estudantes demonstrou ideias condizentes com as ideias científicas atuais, que nesse caso são muito parecidas com as ideias de senso comum, por serem situações muitas vezes não vivenciadas pelos estudantes, mas que frequentemente estão em circulação na televisão e meios eletrônicos de comunicação.

$\mathrm{Na}$ transcrição abaixo, o grupo de estudantes expressa uma ideia adversa do significado de economia contido no texto e no enunciado, tratando a economia de uma nação como sendo apenas diminuição de gastos:

\footnotetext{
"As vezes sim e as vezes não por que nem sempre acontecem a economia de uma nação" (Pedro).
}

Observa-se que a ideia apresentada se contrapõe ao significado de economia que é "o conjunto de atividades desenvolvidas pelos homens visando à produção, distribuição e o consumo de bens e serviços necessários à sobrevivência e à qualidade de vida" (FEAUSP, 2008).

Na transcrição da resposta abaixo o grupo de estudantes afirma que as plantações e os animais morreriam com chuvas constantes. No entanto, essa é uma das situações necessárias para o desenvolvimento das plantações e, consequentemente, a obtenção de alimento para as pessoas e os animais. Acredita-se que os estudantes confundiram o termo chuvas constantes com inundações. 
"O frio elevado, causa uma grande crise na economia de uma nação, pois as plantações e animais morrem devido as constantes chuvas. Com isso a população fica sem condições de se sustentar devido ao alto custo de alimentos que tem que ser exportado de outros lugares" (Maria).

$\mathrm{Na}$ transcrição da resposta abaixo os estudantes trazem um argumento que pode ser considerável, explicitando que o frio elevado aumentaria a venda de aquecedores. No entanto, quando se faz a análise geral essa situação seria insignificante, quando comparado ao que aconteceria com o resto dos fatores econômicos de uma nação.

"O frio elevado poderia afetar uma grande economia de uma não mais também poderia ajudar pois hoje com o frio em exeto podem aumentar as vendas de aquecedores" (José).

$\mathrm{Na}$ transcrição da resposta abaixo, o conceito de calor aparece ainda como uma concepção substancialista, de séculos passados, retomando ideias parecidas com as do calórico de Lavoisier e de outros cientistas daquela época. Também se percebe que os estudantes desse grupo associam verão apenas com épocas quentes e não como uma estação do ano que se refere a uma região da Terra que em determinada época está mais exposta ao sol.

\footnotetext{
"Porque se ficar muito frio as plantações em geral não vingaria, e também tem muitas pessoas que dependem do verão nas praias com barsinhos que só funciona se tiver calor" (Miriam).
}

$\mathrm{Na}$ transcrição da resposta abaixo o grupo de estudantes expõe um argumento interessante. Enquanto os outros grupos relatam apenas que o frio afetaria a economia de uma região, este grupo argumenta que este fato ocorrerá em uma sociedade que não está acostumada ou preparada para o frio elevado.

"Com a chegada do frio a economia seria afetada, numa nação que não esta acostumada com um frio que nunca aconteceu no seu local de moradia, afetaria nos preços de comidas e etc, tudo ficaria mais caro, pois, iria aumentar os preços para como sobreviver nesse clima, por isso é que afetaria a economia de um país" (Miguel). 
Com a análise das respostas dos estudantes foram identificadas algumas "concepções de mundo" a cerca do conceito de frio, das quais aparecem 5 ideias com visões distorcidas do ponto de vista científico da temática sobre o frio, que são apresentadas abaixo:

1. Frio é uma substância;

2. Frio é uma reação do corpo;

3. Frio é a mudança de clima, para climas mais chuvosos ou nublados;

4. Frio causa doenças como gripe, leptospirose entre outas;

5. Tempo é sinônimo de clima.

\section{Conclusões}

Diante do exposto, observa-se que, a partir do diagnóstico acerca das concepções/ideias que os estudantes trazem para a sala de aula, o docente tem condições de planejar práticas problematizadoras que visem colocar os estudantes como sujeitos de sua própria aprendizagem.

Com a aplicação do texto fica nítido o cuidado que se deve ter nas abordagens sociais, culturais, históricas, cotidianas e geográficas que serão utilizadas para abordar o tema de interesse, pois o conhecimento de senso comum enraizado na maioria das pessoas é muito forte e não pode ser confrontado diretamente.

Logo, se busca conscientizar os estudantes da necessidade de ter novos conhecimentos (científicos) mais abrangentes que possam descrever melhor os fenômenos que acontecem no mundo em que vivem.

Assim, dar-se-á necessidade do docente desenvolver práticas que ofereçam condições para que os estudantes tomem consciência de sua existência, e como tal, tomem decisões conscientes em provimento de uma mudança positiva de seu status quo. Nesse sentido surge a necessidade de propor um ensino que oriente os estudantes a atuarem como agentes modificadores de sua realidade. 


\section{Referências}

ARAUJO, A. T. Conceitos de calor e temperatura sob a ótica do momento pedagógico de problematização inicial. 2015. Dissertação (Mestrado em Química) - Centro de Ciências Exatas e da Natureza, Universidade Federal da Paraíba, João Pessoa, 2015.

BACHELARD, G. A Filosofia do Não. Coleção Os Pensadores. São Paulo: Abril Cultural. 1978.

COBERN, W. W. Worldview theory and conceptual change in science education. Science Education, p. 579-610, 1996.

FREIRE, P. Pedagogia do oprimido. 43ª ed. Rio de Janeiro: Paz e Terra, 2005.

FREIRE, P. Pedagogia da autonomia: saberes necessários à prática educativa. $33^{\mathrm{a}}$ ed. Rio de Janeiro: Paz e Terra, 2006.

MORTIMER, E. F. Evolução do atomismo em sala de aula: Mudança de perfis conceituais. Tese (Doutorado em Educação) - Faculdade de Educação, Universidade de São Paulo, São Paulo, 1994.

MORTIMER, E. F. Conceptual change or conceptual profile change? Science \& Education, 4, 265-287, 1995.

MORTIMER, E. F. Construtivismo, mudança conceitual e o ensino de ciências: para onde vamos? Investigações em Ensino de Ciências, p. 20-39. 1996.

POSNER, G. J., Strike, K. A., Hewson, P. W., \& Gerzog, W. A. Accommodation of a scientific conception: Toward a theory of conceptual change. Science Education, p211-227. 1982.

ROMMETVEIT, R. On the architecture of intersubjectivity. In: R. Rommetveit \& R.M. Blakar (Eds.), Studies of language, thought, and verbal communication, London: Academic Press, p. 93-108. 1979. 
VYGOTSKY, L.S. Mind in society: The development of higher psychological process (M. Cole, V. John-Steiner, S. Scribner \& E. Souberman, Eds.). Cambridge, MA: Harvard University Press. 1978.

VIGOTSKI, L.S. A construção do pensamento e da linguagem (P. Bezerra, trad.). São Paulo: Martins Fontes. 2000. 